\title{
Waldegrave wants to carve up SERC and create stronger political links
}

London. The British government is proposing to break down what officials describe as a "Chinese wall" between science and the political process by appointing a directorgeneral in the government's Office of Science and Technology (OST) to take direct responsibility for the work of the research councils.

In doing so, William Waldegrave, Chancellor of the Duchy of Lancaster and the cabinet minister responsible for science, is seeking to reverse a tradition of protecting the administration of science from direct political influence. The tradition began with the creation in 1920 of the Medical Research Council - and the formulation of the socalled 'Haldane Principle' — but has now left Britain out of step with most of its economic competitors.

The government is also planning to carve up the responsibilities of the Science and Engineering Research Council (SERC) and to create two new councils, one for particle physics and the other for engineering and physical sciences. In addition, SERC's biological research will be merged into the Agricultural and Food Research Council to form a single Biotechnology and Biology Research Council.

The creation of a director-general for research councils and the splitting up of the SERC (the other four councils will remain intact) are the most radical changes to emerge from the government's White Paper (policy document) on science, which was published this week. The White Paper will disappoint those who had been hoping for a major increase in research funds as well as those wanting a strong, centralized science policy; individual government departments will retain most of their existing responsibilities, and there will not be large amounts of money for new initiatives.

In contrast, Waldegrave is seeking to achieve the twin goals of boosting wealth creation and the quality of life by bringing the world of science and engineering decision-making into the political process to ensure that this process is "infested" with both activities. At the same time, all the research councils will be given an explicit mission of working towards these twin goals.

Since the early 1970 s, the work of the research councils has been coordinated by the Advisory Board for the Research Councils (ABRC), which in particular has advised the government on the distribution of funds between the councils. But the creation last year of OST has made the role of this body ambiguous.
The government has now decided to abolish it, and to absorb executive responsibility directly into the OST. The new director-general for research councils will be responsible to the permanent secretary of the OST for the way that individual research councils are run and for ensuring collaboration between them.

The abolition of the ABRC - and at the same time of the Advisory Council on Sci-

\section{IMAGE UNAVAILABLE FOR COPYRIGHT REASONS}

Waldegrave wants research to be part of politics.

ence and Technology - will mean a general shake-up in the structure of advisory committees. The main lines of government policy will now be discussed by a new high-level Council on Science and Technology, which will be chaired by the minister for science on behalf of the prime minister, and whose members will include representatives of industry, government and the academic world.

The Council will have a secretariat provided by the OST and will be headed by the government's chief scientist, Bill Mitchell. In addition, the new director-general for research councils will also have his or her own advisory group of outside experts.

The OST will not, as some had originally proposed, take over the research budgets of any of the individual government departments. Attempts to do this have been strongly resisted by the departments themselves, and the government now appears to believe that it would be a mistake to centralize the direction of departmental policies.

However the OST will keep a close eye on what departments are doing with their science budgets. Each department will be required to publish research spending plans, which will be compiled into a single document published annually as a five-year "forward look".

This exercise will allow the OST - which will also carry out a series of "technology foresight" exercises to develop agreement on long-term research needs - to make suggestions to departments about what research they should or should not be carrying out to achieve these needs. Waldegrave himself sits on a leading cabinet spending committee, allowing him to keep departmental research spending plans under close review.

The splitting of SERC will mean that those activities considered to contribute towards the government's goal of wealth creation (including, for example, the new Innovative Manufacturing Initiative; see page 295) will come under the responsibility of the planned Engineering and Physical Sciences Research Council. The creation of a single Biotechnology and Biological Research Council is in line with proposals made several years ago. Giving particle physics its own research council will mean that additional costs incurred by swings in international exchange rates will now be jointly absorbed by all the research councils, and not just the SERC.

Waldegrave has decided to remove the uncertainty that has recently been hanging over university scientists by allowing the Department of Education to keep responsibility for funding the basic platform of university research through the three higher education funding councils. In addition to maintaining the dual support system in this way, the government also intends to improve career prospects for university scientists by introducing an extra year of study, leading to an MSc, for all graduates before starting postgraduate research. This period will be used to assess the suitability of an individual for a research career.

In addition, OST is considering the introduction of longer-term doctoral fellowships. And both universities and other institutions receiving government research funds will be required to demonstrate that they are taking steps to exercise greater concern for the career development of their research staff.

Finally, the government has decided to focus its efforts to stimulate public understanding of science on Britain's secondary schools. A fund will be set up to subsidize such efforts, organized on a regional basis, to which private bodies will also be asked to contribute.

In addition, a series of activities is planned leading to a major event in 2001, which marks the 150th anniversary of the Great Exhibition in London. But Waldegrave is clearly hoping to do better than Prince Albert in injecting science and technology into the political culture of contemporary Britain.

David Dickson 